\title{
8
}
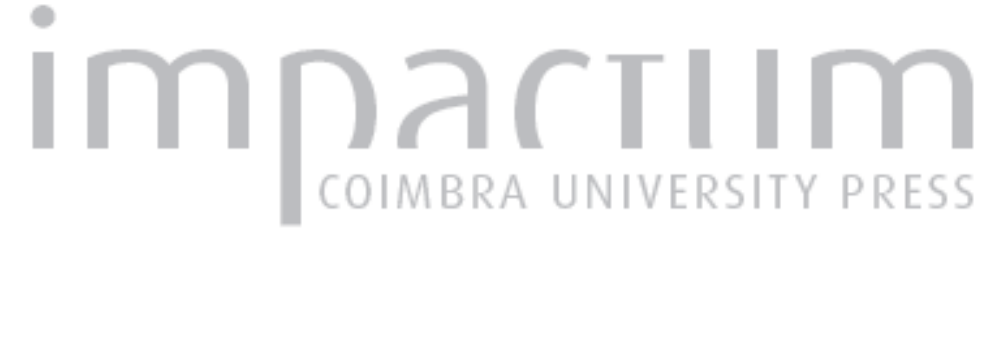

\section{Fortuna de Verdi no teatro de São Carlos de Lisboa nos séculos XIX e XX}

Autor(es): $\quad$ Carvalho, Jorge Vaz de

Publicado por: Imprensa da Universidade de Coimbra

URL persistente:

URI:http://hdl.handle.net/10316.2/42426

DOI:

DOl:https://doi.org/10.14195/0870-8584_8_2

Accessed : $\quad$ 26-Apr-2023 12:28:10

A navegação consulta e descarregamento dos títulos inseridos nas Bibliotecas Digitais UC Digitalis, UC Pombalina e UC Impactum, pressupõem a aceitação plena e sem reservas dos Termos e Condições de Uso destas Bibliotecas Digitais, disponíveis em https://digitalis.uc.pt/pt-pt/termos.

Conforme exposto nos referidos Termos e Condições de Uso, o descarregamento de títulos de acesso restrito requer uma licença válida de autorização devendo o utilizador aceder ao(s) documento(s) a partir de um endereço de IP da instituição detentora da supramencionada licença.

Ao utilizador é apenas permitido o descarregamento para uso pessoal, pelo que o emprego do(s) título(s) descarregado(s) para outro fim, designadamente comercial, carece de autorização do respetivo autor ou editor da obra.

Na medida em que todas as obras da UC Digitalis se encontram protegidas pelo Código do Direito de Autor e Direitos Conexos e demais legislação aplicável, toda a cópia, parcial ou total, deste documento, nos casos em que é legalmente admitida, deverá conter ou fazer-se acompanhar por este aviso. 


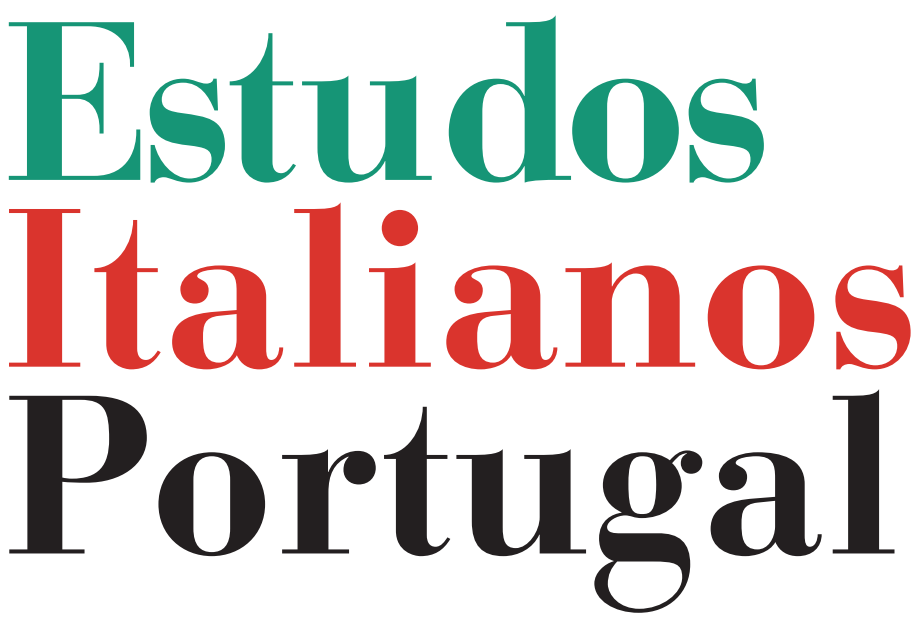

Instituto

Italiano

de Cultura

de Lisboa

Nova Série

$\mathbf{N}^{\circ} \mathbf{8}$ 


\title{
FORTUNA DE VERDI NO TEATRO DE SÃO \\ CARLOS DE LISBOA NOS SÉCULOS XIX E XX
}

\author{
Jorge Vaz de Carvalho*
}

AQUELE QUE É CONSIDERADO unanimemente o maior génio da ópera italiana e um dos maiores compositores da história da música não foi, como Wagner, um formulador de teorias programáticas, nem se afirmou por criaçóes de radicalismo revolucionário. Preferimos observar a obra de Giuseppe Verdi como um progresso construtivo capaz de recusar a inércia das convençốes sem fazer tábua rasa das tradições. O certo é que firmou a estética operática ganhando o favor do público por todo o mundo. Este texto homenageia, no bicentenário do nascimento, o rústico rapazinho que, em 10 Outubro de 1813, num lugarejo obscuro chamado Le Roncole, perto de Busseto, nasceu francês (o ducado de Parma era, então, parte napoleónica de Itália), registado no município com nomes franceses (Joseph Fortunin François), e cujo patronímico se

* Cantor lírico de carreira internacional, é licenciado em Línguas e Literaturas Modernas pela Universidade Clássica de Lisboa, Mestre em Literaturas Comparadas pela Universidade Nova de Lisboa e Doutorado em Estudos de Cultura pela Universidade Católica de Lisboa. O seu trabalho literário inclui obras de poesia, conto, ensaio (ganhou os prémios PEN-Clube e Jorge de Sena para a obra Sinais de fogo de Jorge de Sena como romance de formação) e tradução (Ciência nova de Giambattista Vico venceu o Prémio de Tradução Científica e Técnica FCT/União Latina). Exerce actividade de articulista e de conferencista, no país e no estrangeiro. Foi Director da Orquestra Nacional do Porto e Director do Instituto das Artes. É professor da Faculdade de Ciências Humanas da Universidade Católica Portuguesa. 
transformou num símbolo de independência nacional e da luta patriótica pela unificação de Itália.

$\mathrm{Na}$ vida de um ser as aptidóes musicais revelam-se natural e prontamente, ou serão insignificantes. O organista de San Michele, Don Baistrocchi, cedo persuadiu o pai de Verdi de que valeria a pena comprar-lhe a "espineta miserável" de um padre das redondezas, e que, reparada por Stefano Cavalletti, foi seu instrumento de aprendizado. Aos dez anos, enviaramno para estudar em Busseto e, morto Baistrocchi, foi nomeado organista, em sua substituição (1825). Acolhido na casa do mercador Antonio Barezzi, tornou-se, aos treze anos, compositor de marchas e aberturas para a banda de música da Sociedade Filarmónica de que aquele era presidente, de árias e cantatas para os cantores locais apresentarem na igreja ou no teatro, e tocava variaçóes pianísticas em concertos. Apesar do ambiente musical modesto, tal actividade proporcionou ao adolescente um porfioso adestramento. Também na casa de Barezzi se apaixonou pela filha mais velha, Margherita, que viria a ser (em 4 de Maio de 1836) a sua primeira mulher. A bolsa do futuro sogro e a da instituição local de Monte di Pietà asseguraram a Verdi os estudos particulares e a estada em Miláo, onde, em Junho de 1832, lhe recusaram a entrada no Conservatório.

A estreia da primeira ópera, Oberto, conte di San Bonifacio, a 17 de Novembro de 1839, no Teatro alla Scala de Miláo, foi centro dos mais trágicos desgostos afectivos que Verdi poderia sofrer: menos de um mês antes (em 22 de Outubro), morrera o filho Icilio; a filha tinha morrido no ano anterior (em 12 de Agosto); a mulher seguiu-os, em 18 de Junho de 1840. Como teria conseguido Verdi, ele próprio com problemas de saúde e pouco dinheiro, o espírito necessário para compor e estrear a ópera cómica Un giorno di regno, no Scala, a 5 de Setembro de 1840, e ainda suportar o seu fracasso? Estas duas óperas inaugurais não foram estreadas em Lisboa. Mas, ao longo da segunda metade do século XIX, Verdi 
tornar-se-ia, à semelhança da pátria italiana, o compositor preferido do palco operático do Teatro de São Carlos, e a ele regressaria em força após a reabertura nos anos 40 do século XX.

Em 9 de Março de 1842, o Scala de Milão póe em cena a ópera com que Verdi consideraria ter começado a sua carreira de compositor: Nabucco. Identificada com os ideais do Risorgimento italiano, a melancolia e aspiraçóes libertárias de um povo cativo contra o jugo estrangeiro, a força do drama musical supera a alegoria ideológica. Foi um sucesso capaz de congregar as emoçóes individuais e os sentimentos colectivos, entusiasmar os sonhos políticos tanto quanto as consciências estéticas. (Lembremos que o papel de Abigaille era cantado por Giuseppina Strepponi, com meios vocais limitados, em precoce fim de carreira, mas com atributos femininos para se tornar a companheira de Verdi até ao fim dos seus dias, relação que duraria mais de cinquenta e cinco anos). No Teatro de São Carlos de Lisboa, Nabucco estreou-se a 16 de Abril de 1847, com o barítono português Eduardo Medina Ribas no papel titular. Regressaria a 2 de Outubro de 1852, sendo protagonista Ottavio Bertolini, e, com alguma regularidade até 82-83. No século XX, após a temporada de 1903-1904 (com Giuseppe Pacini), Nabucco esperaria cinquenta anos para voltar a São Carlos, em 52-53, com o grande Tito Gobbi e direcção de Oliviero de Fabritiis. Doze anos volvidos, o público escutaria Giangiacomo Guelfi, na temporada de 1965-66, tendo a seu lado a "Abigail" de Elena Suliotis e o "Zaccaria” de Paolo Washington. Trinta anos depois, abriu a temporada de 1995-1996, com Giorgio Zancanaro como protagonista e a bela direcçáo de Giuliano Carella.

Seguem-se na produção operática de Verdi, a ritmo alucinante, as criaçóes de I Lombardi alla Prima Crociata, a 11 de Fevereiro de 1843; de Ernani, a 9 de Março de 1944, no Teatro La Fenice de Veneza a primeira colaboração com o libretista Francesco Maria Piave, enquanto se afirmava como 
o principal compositor italiano e dava início à projecção internacional; a 3 de Novembro, estreia I due Foscari, no Teatro Argentina de Roma; Giovanna d'Arco, a 15 de Fevereiro de 1845, no Scala de Milão; Alzira, no San Carlo de Nápoles, a 12 de Agosto; Nabucco e Le Proscrit (adaptação francesa de Ernani, que Victor Hugo não consentiu ver posto em ópera) triunfam em Paris; em 1846, Attila, que estreara a 17 de Março, no La Fenice de Veneza, entusiasma toda a Itália, reforçando mais a identificação da música de Verdi com a causa nacionalista. Não são tempos de grande renovação estética estes a que Verdi se referiria como os seus "anni di galera" mas, sobretudo, de trabalho insano sobre uma fórmula mais ou menos inspirada de sucesso. Consolida-se a tipificação romântica do melodrama verdiano em recorrentes elementoschave: pátria (luta entre opressor e oprimido), liberdade (luta entre tirano prepotente e herói rebelde ou excluído), honra (luta entre crua vileza e elevados princípios morais), amor (sob várias formas, paternal, filial, fraternal, sensual, paixóes destemperadas, luta entre ódio irado e ternura, cupidez e pureza) e dor (experiência transfiguradora através da qual se humanizam os mortais).

Em Lisboa, I Lombardi estreia-se dois anos após a criação italiana, em 10 de Março de 1845, e passa a ser título frequente durante um quarto do século XIX, repetido nas temporadas das décadas de 40, 50 e até 68-69. No início do século XX é incluído ainda na programação de 1903-04, mas será logo abandonado, ressurgindo fugazmente na temporada de 1987-88, com vários cantores portugueses (Elizete Bayan, Carlos Fonseca, Manuela Castani), a "Giselda" de Silvia Mosca, Michele Pertusi no papel de "Pagano" e, sobretudo, o "Oronte" do tenor inigualável que foi Carlo Bergonzi. Ernani não demorou um ano a estrear-se em Lisboa, no primeiro dia de Janeiro de 1945, com Enrico Tamberlick no protagonista. A partir daí, foi presença quase ininterrupta nas temporadas do Teatro de São Carlos até ao fim do sécu- 
lo XIX. Com o século XX, injustamente, declina: surge nas temporadas de 1903-04 e 1907-08, mas só voltará na íntegra em 1969-70, com um elenco que incluía o tenor Amedeo Zambon ("Ernani"), o soprano Antonietta Stella ("Elvira") e o barítono Franco Bordoni ("Carlos V"), sob a batuta de Manno Wolf-Ferrari. I due Foscari goza também de uma rápida estreia em São Carlos, a 5 de Março de 1846, e durante cerca de vinte anos surge sete vezes na programação, para se eclipsar até hoje. Giovanna d'Arco sofre ainda menor apreço: após a estreia, a 10 de Novembro de 1847, a sua fortuna termina no mês seguinte, para não mais regressar a São Carlos. Attila, por sua vez, estreado um ano depois de Itália, em 5 de Abril de 1947, suporta em dez anos cinco temporadas e cai no esquecimento, para ser efemeramente resgatado nos anos 80 do século $\mathrm{XX}$, na produção apresentada em duas programaçóes seguidas, as de 1984-85 e 85-86.

Em 1847, ano de estreia da ópera I Masnadieri, em Londres (22 de Julho), onde também I due Foscari triunfa no Covent Garden, e I Lombardi se vê transformada em Jérusalem para a cena do Théâtre de l'Opéra de Paris (26 de Novembro), os florentinos assistiram ao primeiro encontro de Verdi com Shakespeare, e aplaudiram no Macbeth (estreado em 14 de Março) um progresso original: sobressaem, mais que os grandes ideais colectivos, as paixôes terrivelmente dilemáticas e excessivas do indivíduo, colhidas na íntima efervescência; sem perder de vista o espectáculo da carne, coraçấo e sangue, vai para além do colorido e dos efeitos exteriores, através do estudo psicológico da alma humana - o que implica novas soluçôes estilísticas, uma substância bem mais rica e a cedência da mera exibição belcantista à profunda verdade dramático-musical das personagens. A sua arte não atingiu ainda o vértice, mas experimenta já maior reflexão, é mais elaborada, culta. Verdi tem uma atitude inédita de tirânica exigência para com a preparação musical e cénica: sucessivos ensaios com piano e orquestra até polir a expressão 
rigorosamente adequada. Verdi dedicou ao sogro, Antonio Barezzi, essa ópera que preferia a todas as outras que compusera. Com I Masnadieri repete-se, no Teatro de São Carlos, a fortuna das óperas de juventude de Verdi: estreia mais ou menos rápida (em 8 de Março de 1849), cinco presenças nas temporadas até 62-63, e eclipse posterior. A rara novidade dramática de Macbeth não foi plenamente compreendida: estreou em 13 de Janeiro de 1849 e durou, no século XIX, catorze regulares temporadas até 82-83; depois de 1904-05, só voltaria à programação de São Carlos em 1959-60 (nas vozes de Paolo Silveri, Shakeh Vartenissian, Mirto Picchi, Paolo Washington) e mais tarde em 1980-81 (com Renato Bruson e Adelaida Negri como casal trágico).

$\mathrm{O}$ ano de 1848, em que Verdi estreia Il Corsaro, em Trieste (25 de Outubro), é o da morte de Donizetti (Bellini já expirara, em 1835) e da sublevação revolucionária de várias cidades italianas. Em Milão, capital da província austríaca da Lombardia, donde os austríacos haviam sido expulsos, e que depois reocupam, Verdi encontra Mazzini, o escritor e lutador pela unidade da nação italiana, cujos ideais enformaram basicamente o pensamente do compositor ao longo da vida. Quando Mazzini parte para o exílio, Verdi regressa a Paris, com a ideia de compor uma nova ópera patriótica: será La Battaglia di Legnano, criada a 27 de Janeiro, em Roma. Limitado pela censura contra novos assuntos de teor patriótico, Verdi vira-se para um libreto baseado na obra Kabale und Liebe, de Schiller: a estreia de Luisa Miller ocorre a 8 de Dezembro, em 1849, no San Carlo de Nápoles, e representa, para alguns, uma nova maneira verdiana, em que o grandioso deixa lugar ao aprofundamento psicológico dos personagens, revelando um pensamento musical de maior maturidade, expresso no trabalho orquestral, sensível no ganho de equilíbrio entre música e acção. Menos de um ano depois, em 16 de Outubro de 1850, Stiffelio é criado no Teatro Grande de Trieste. De todas estas óperas, apenas Luisa Miller é chamada 
ao palco de São Carlos, na estreia, em 22 de Junho de 1851, na temporada de 1850-51, e depois em mais oito até à de 86-87; quase cem anos passaram até se voltar a ouvir, na programação de 1982-83, protagonizada por Mara Zampieri.

Destes tempos de produção ininterrupta despontam justamente três óperas como os cumes mais sublimes da genialidade de Verdi, êxitos populares eternos nos palcos de todo o mundo. Em 11 de Março de 1851, Rigoletto estreia-se no La Fenice de Veneza, início do extraordinário triunfo por todo o mundo (excepto em França, e não antes de 1857, porque foi vetada por Victor Hugo, autor da peça em que se baseia, Le roi s'amuse). No Teatro de São Carlos, desde a estreia em 29 de Janeiro de 1854, Rigoletto foi chamado à programação dezenas de vezes, tendo sido escutado com extraordinários intérpretes do canto lírico: os primeiros foram o barítono Ottavio Bartolini ("Rigoletto"), o tenor Corrado Miraglia ("Duque de Mântua") e o soprano Amalia Anglès Fortuni (“Gilda”). O que não daria para ter ouvido o Rigoletto de 19 de Março de 1903, com Riccardo Stracciari, Enrico Caruso e Regina Pacini; o de 16 de Dezembro de 1926, com Carlo Tagliabue, Luigi Marini e Bidú Sayão! Os anos 40 e 50 trariam a Lisboa protagonistas da dimensão dos barítonos Gino Bechi, Ugo Savarese; os tenores Mario Filippeschi, Cesare Valletti; o soprano Alda Noni; os baixos Giulio Neri e Italo Tajo. O único Rigoletto dos anos 60, em abril de 1962, reuniu um elenco extraordinário: Sesto Bruscantini, Alfredo Kraus e Gianna D’Angelo. O tenor Alfredo Kraus, tornou-se o "Duque de Mântua" titularíssimo durante os anos 70: ao lado de Piero Cappuccilli e Margherita Guglielmi (Março de 1971); com Franco Bordoni e Ileana Cotrubas (Março de 1975); com Renato Bruson e Elisete Bayan (Abril de 1979). De registar, em Maio de 1987, a "Gilda” de Elvira Ferreira.

$\mathrm{O}$ ano de 1853 assiste a duas das maiores criaçóes verdianas, compostas quase simultaneamente. A 19 de Janeiro, no Teatro Apollo de Roma, Il trovatore, que Lisboa recebe 
menos de um ano depois, a 17 de Abril de 1854, sendo intérpretes principais o tenor Corrado Miraglia ("Manrico"), o soprano Anaïs Castellan ("Leonora"), o barítono Ottavio Bartolini ("Conde de Luna") e o meio-soprano Ersilia Agostini ("Azucena”). Até 1890, só por seis vezes a obra não foi programada, regressando mais duas até ao fim do século (1895-96 e 97-98). No século seguinte, além de duas programaçōes nos anos vinte (1923-24 e 26-27), ressurgiu com um elenco insuperável e hoje inimaginável de reunir, em Março de 1948, Beniamino Gigli, Maria Caniglia, Gino Bechi, Ebe Stignani, dirigidos por Antonino Votto (!); com elencos notáveis em Março de 1959, Giuseppe Savio, Régine Crespin, Ettore Bastianini, Lucia Danieli, Março de 1963, Carlo Bergonzi, Mirella Parutto, Sesto Bruscantini e Angelica Morfoniou, e Março de 1973 (Giuseppe Giacomini, Liliana Molnar-Talajic, Piero Cappuccilli, Fiorenza Cossotto). Em 1978 cantaram Vincenzo Bello, Mara Zampieri, Piero Cappuccilli, Fiorenza Cossotto. Houve ainda elencos interessantes em 1980-81 e 1990-91.

Pouco depois de Il trovatore, a 6 de Março de 1853, no La Fenice de Veneza, estreia-se La Traviata, a que Lisboa assiste, pela primeira vez, em 29 de Outubro de 1855, com a grande Marietta Spezia na protagonista, o tenor Ambrogio Volpini como "Alfredo" e o barítono Ottavio Bartolini como pai "Germont". Nos quarenta e cinco anos seguintes terá falhado apenas nove temporadas, durante os anos 90 é programada cinco vezes e está presente sete vezes nas duas primeiras décadas do século XX. Nos anos 40 e 50 ouvem-se elencos extraordinários: em 1948, Maria Caniglia, Beniamino Gigli e Gino Bechi (!); em 1950, Renata Tebaldi, Gianni Poggi e Enzo Mascherini; em 1952, Margherita Carosio, Giuseppe Campora e Afro Poli; em 1957, Virginia Zeani, Flaviano Labò e Carlo Tagliabue. Porém, La traviata que ficou literalmente gravada para a história foi a de Março de 1958, quando Lisboa recebeu a mítica Maria Callas, mas também 
o ardente "Alfredo" do magnífico Alfredo Kraus e o "Germont" de Mario Sereni. Era impossível ascender ao mesmo fulgor nas programaçóes das décadas de 60, em Março de 64 com Mary Costa, Alain Vanzo e Licinio Montefusco, e em Março de 1968, com a grande Renata Scotto, Ottavio Garaventa e Attilio D'Orazi. Mas os anos 70 trazem a Lisboa outra La traviata mítica, ainda insuficientemente prezada: além do facto histórico de a última récita, no Coliseu dos Recreios, ter acontecido na noite da Revolução dos Cravos, a 18 e 21 de Abril, o São Carlos dignificava-se com um elenco constituído pela estupenda Joan Sutherland, de novo o magnífico Alfredo Kraus e o excelente Giorgio Zancanaro, dirigidos pelo maestro Richard Bonynge. A popularidade de La traviata trouxe-a de volta, obviamente sem o mesmo fulgor, em 1979, em Maio de 82 (com Elizete Bayan e Carlo Bergonzi), em 1987 (em que eu próprio me estreei no papel de "Germont", ao lado de Elizete Bayan e Vincenzo Bello) e, obviamente, depois.

A ópera Les vêpres siciliennes estreia na sua versão francesa original, em 13 de Junho de 1855, na ópera de Paris. Após vicissitudes previsíveis com a censura italiana da época, que incluíram a mudança de tempo e localização da Sicília (o libreto estava baseado nos célebres acontecimentos históricos de 1282) para o Portugal de 1640, à beira de se libertar do domínio espanhol, acaba por ser o texto italiano e a versão de 1861, pós unificação italiana, a perdurar, sob o título $I$ Vespri Siciliani. No Teatro São Carlos de Lisboa, I vespri siciliani estreou em 12 de Março de 1857, mas náo fez mais de seis temporadas no século XIX e outras duas no início do século XX (1903-04 e 04-05), retirando-se da programaçáo posterior. Aroldo, ópera adaptada de Stiffelio, estreada com enorme sucesso em Rimini, a 16 de Agosto de 1857, acabou por não se impor em Itália, tal como em Lisboa, onde, após a estreia em 25 de Novembro de 1851, só voltaria duas vezes, nas temporadas de 1860-61 e 1863-64. 
A ópera Simon Boccanegra, criada a 12 de Março de 1857 no Teatro La Fenice de Veneza, e desprezada pelo palco de São Carlos no século XIX (após a estreia, em 29 de Outubro de 1960, só seria programado em 1886-87), teve nos anos 50 do século XX um ressurgimento importante (temporadas de 1951-52, 54-55 e 56-57). Decerto devido aos elencos da mais elevada estirpe, em que preponderava o insuperável Tito Gobbi sempre como protagonista e, sucessivamente as "Maria" de Maria Caniglia, Antonietta Stella e Marcella Pobbe, os "Gabriele Adorno" de Gino Penno, Mario Filippeschi e Franco Corelli; Rolando Panerai foi o "Paolo Albiani" de 1952; e os "Jacopo Fiesco" de Giulio Neri (em 52 e 55) e Boris Christoff (em 57). Tito Gobbi voltou para cantar o "Simon Boccanegra" da temporada de 1961-62 e Giangiacomo Guelfi o da temporada de 1967-68. Dez anos depois, o São Carlos ouviu o grande Piero Cappuccilli como protagonista, tendo a seu lado, a "Maria" de Mara Zampieri.

Graves problemas com a censura napolitana perturbam, em 1858, a criação de Un ballo in maschera: Verdi, que agora dominava a cena italiana, não aceitou fazer as modificaçóes impostas e a ópera só será estreada um ano depois, a 17 de Fevereiro de 1859, no Teatro Apollo de Roma. No libreto, a conspiração política que levara ao assassinato do rei Gustavo III da Suécia suavizara-se em crime passional do governador de Boston. Há revoltas a rebentar por toda a Itália e, com elas, a guerra (23 de Abril). A primeira unidade italiana só será atingida nos finais de 1860 . Entretanto, a 19 de Agosto de 1859, Giuseppe (Verdi) desposa Giuseppina (Strepponi). Meio século antes da república substituir a monarquia em Portugal, estreia em Lisboa Un ballo in maschera, a 15 de Abril de 1860, mantendo-se durante dezanove temporadas mais ao longo do século XIX (refira-se que, em 1887, cantaram os célebres irmáos António e Francisco de Andrade). Depois de quatro programaçóes na primeira década do século XX (em que puderam ser ouvidos, por exemplo, o soprano 
Matilde de Lerma, o barítono Giuseppe De Luca ou o tenor Francisco Viñas), a ópera regressará na década de 40 do século XX: em 1946-47 e 48-49, distribuída respectivamente a Elisabetta Barbato e Iolanda Magnoni ("Amelia"), Fedora Barbieri e Ebe Stignani ("Ulrica"), Giuseppe Momo e Mario del Monaco ("Riccardo") e Gino Bechi ("Renato"). Depois, em 1953-54, regressa a Barbato, com Lucia Danieli, Mirto Picchi e Tito Gobbi. Nos anos 60 ouvem-se, por exemplo, os sopranos Mariella Parutto e Emma Renzi, os tenores Giuseppe Di Stefano e Renato Cioni, os barítonos Antonio Boyer e Piero Cappuccilli. A temporada de 1975-76 apresenta um excelente elenco: Rita Orlandi-Malaspina, Viorica Cortez, Carlo Bergonzi e Matteo Manuguerra. As récitas de 83 ainda se dáo ao luxo de programar os notáveis Carlo Bergonzi e Piero Cappuccilli e as de 1990 oferecem Natalia Troitskaya, Fiorenza Cossotto, Taro Ichiara e Paolo Gavanelli.

Cavour, a quem Verdi chama "o pai da Pátria", consegue persuadi-lo a deixar-se eleger deputado (30 de Janeiro de 1861) da nova nação italiana, cujo parlamento abre em Turim, a 19 de Fevereiro. A 17 de Março, é proclamado o novo reino de Itália, e Vittorio Emanuele II o seu rei. Cavour sobrevive apenas dois meses a tal alegria. Verdi ocupa o lugar de deputado a contra-gosto e, assim que pode, póe fim à carreira política (1865) que, verdadeiramente nunca exerceu. Entretanto, a ópera La forza del destino, encomenda do Czar da Rússia, estreia a 10 de Novembro de 1862, em São Petersburgo, com estrondoso sucesso, que repetirá em Madrid, no ano seguinte. Lisboa recebe-a a 15 de Março de 1873, com Antonietta Fricci-Baraldi ("Leonora"), Giuseppe Fancelli ("Don Alvaro") e Francesco Pandolfini ("Don Carlos”) nos papéis principais e, nessa década de 70, há mais quatro programaçóes. Depois, apenas uma, em 1898-99. O século XX recupera-a, na temporada de 1945-46, com um elenco de primeira água, Maria Caniglia, Beniamino Gigli, Gino Bechi, Giulio Neri (!); e logo na seguinte, 46-47, com 
Elisabetta Barbato, Giuseppe Momo, os mesmos Bechi e Neri, além da "Preziosilla" de Fedora Barbieri. Talvez a sua reputação de ópera maldita, portadora de azar, tanto quanto a dificuldade de reunir um elenco à altura dos vários papéis, limite a sua mais constante programação. Ao São Carlos de Lisboa só voltaria, por duas vezes, na temporada de 1971-72, com Anna Tomowa-Sintow, Carlo Bergonzi e Lucian Marinescu, e na de 1979-80, com Mara Zampieri, Juan Lloveras e Giorgio Zancanaro.

Em 1863, surge em Itália o movimento artístico dos Scapigliati, contra os valores estéticos dominantes, representados, segundo ele, por Manzoni, na literatura, e por Verdi, na música. Ironia será que uma das suas cabeças dominantes, Arrigo Boito, se viesse a tornar o libretista das duas últimas óperas verdianas. Certo é que todas as criaçóes musicais do grupo envelheceram muito mais e mais rapidamente do que as do seu alvo primordial. Em 1867, Verdi começa por perder o pai (14 de Janeiro) e acaba perdendo (Dezembro) a fiel colaboraçáo do libretista Piave, acometido por uma apoplexia (morrerá a 5 de Março de 1876). Entretanto, o modesto sucesso inicial do Don Carlo, em Paris (11 de Março de 1867), foi-se ampliando, até ao grande triunfo bolonhês, após diversas revisóes, em 27 de Outubro de 1867. O ano seguinte, em que Verdi, após vinte anos de ausência, regressa a Milão e prepara, para o Scala, um revisão de La forza del destino (que triunfará em 27 de Fevereiro de 1869), assiste à morte de Rossini. O Don Carlo veio a Lisboa, pela primeira vez, em 21 de Dezembro de 1871, ano em que, na sequência da guerra Franco-Prussiana e do armistício de Versailles (28 de Janeiro), Vittorio Emanuele se apoderara do território romano e fizera de Roma a nova capital, concluindo a unidade italiana. No século XIX, regressou ao São Carlos nas temporadas de 80-81 e 84-85. No século XX, depois de aparição isolada em 1904-05, beneficia de três programaçóes fulgurantes na década de 50: 1950-51, com Mirto Picchi ("Don Carlo”), Enzo 
Mascherini ("Rodrigo"), Maria Caniglia ("Isabel de Valois"), Ebe Stignani ("Eboli”), Italo Tajo ("Filipe II”), Giulio Neri ("Grande Inquisidor"), 1953-54, com Elisabetta Barbato, Giulietta Simionato, Mirto Picchi, Tito Gobbi, Italo Tajo, Bruno Sbalchiero; 1955-56, com Anita Cerquetti, Giulietta Simionato, Carlo Bergonzi, Giuseppe Taddei, Boris Christoff, Marco Stefanoni (!). Apesar da inegável qualidade dos intérpretes, era impossível atingir globalmente semelhantes cumes nos regressos do Don Carlo em 1963-64 e 1970-71. Em 1976-77, reuniram-se Mara Zampieri, Viorica Cortez, Giuliano Cianella, Mario Zanasi, Cesare Siepi.

O ano de 1871 é, para Verdi, o da criação da Aida, no Cairo (24 de Dezembro), para comemorar a abertura do Canal do Suez. Triunfo que se repetirá no Scala de Miláo, na estreia italiana que envolveu profundamente empenhado o próprio compositor, em 8 de Fevereiro de 1872. A ópera fixou-se como uma das mais populares e aclamadas do repertório verdiano. Em Lisboa, desde a sua estreia, com a "Aida" de Carolina de Cepeda, a "Amneris" de Marietta Biancolini, o "Radamès" de Luigi Bolis, o "Amonasro" de Gottardo Aldighieri, o "Ramfis" de Tommaso Della Costa, em 6 de Fevereiro de 1878 , e até 1890 , a partitura, o exotismo e aparato cénico deslumbraram o público, tornando a sua programação constante (só faltou na temporada de 80-81). No século XX, entre 1900-01 e a década de 20, foi apresentada treze vezes, com um êxito sem precedentes e cantores da envergadura de Eva Tetrazzini, dos tenores António de Andrade ou Francisco Viñas, dos barítonos Riccardo Stracciari ou Carlo Tagliabue. $\mathrm{Na}$ gloriosa década de 40 e 50 do século XX, Lisboa oferece elencos inigualáveis: em 1946-47, Maria Caniglia, Ebe Stignani, Mario Filippeschi, Gino Bechi, Giulio Neri; em 47-48 e 49-50 só muda o tenor, respectivamente Beniamino Gigli e Mario Del Monaco. Aida volta nas temporadas de 1952-53 e de 54-55 (esta com Antonietta Stella, Miriam Pirazzini, Mario Filippeschi, Tito Gobbi, Giulio Neri); de 1960-61 e 
de 68-69 (com Elena Suliotis, Fiorenza Cossotto, Carlo Bergonzi, Edoardo Cittanti, Ivo Vinco); depois, em 75-76, 7980, 80-81 (as duas últimas com a "Aida" de Mara Zampieri) e 88-89.

A morte de Manzoni, a 22 de Maio de 1873 (poucos meses depois da morte de Wagner, a 13 de Fevereiro), inspira ao ateu Verdi uma merecida homenagem, na forma de um Requiem, que será criado no ano seguinte, no primeiro aniversário dessa morte funesta para as letras italianas. A obra dá a volta ao mundo e Verdi é nomeado senador do reino de Itália. Compóe agora menos mas, ainda assim, revê Simon Boccanegra para o Scala de Miláo (24 de Março de 1881) e encurta o Don Carlos na versão em IV actos (1884). Só a 5 de Fevereiro de 1887, no Teatro alla Scala de Miláo, se dará a estreia absoluta de uma nova ópera: Otello, o regresso ao sempre amado Shakespeare, 40 anos depois de Macbeth, com um libreto de Arrigo Boito, que obtém uma recepção delirante e ganha o entusiasmo de toda a Europa. A dificuldade de reunir um trio de cantores com nível suficiente para desempenhar os papéis principais (sobretudo as cores necessárias ao valoroso protagonista, da suavidade à pura potência, e ao "Iago", que pede um cantor-actor inteligente, versátil e de subtis cambiantes) não pode deixar de diminuir a frequência das programaçóes no mundo inteiro. Mas tal obriga também, como raras óperas, a um critério escrupulosíssimo no momento da escolha do elenco. Otello vem a Lisboa na temporada de 1888-89, com Augusto Brogi (“Otello"), Mario Battistini ("Iago") e Eva Tetrazzini ("Desdemona”). Sucedem-se outras cinco temporadas no mesmo século e seis nas primeiras duas décadas do século XX. De volta em 1951-52, é oferecido ao público de São Carlos o melhor elenco possível na época, hoje em dia não mais do que sonhável: Ramon Vinay, Tito Gobbi e Antonietta Stella (!). Em 1952-53 apenas muda a "Desdemona" de Rina Malatrassi. Em 1964-65, são as vozes de James MacCracken, Giangiacomo Guelfi e 
Elena Suliotis. Em 1971-72, "Otello" é Charles Craig e em 1977-78 é Richard Cassily. Em 1989-90, São Carlos recebe, pela única vez, o tenor Placido Domingo.

Verdi surpreende cinco anos depois, em 9 de Fevereiro de 1893, no Scala de Miláo, com uma ópera de carácter e invenção dramática, melódica e orquestral de inesperada novidade: Falstaff, uma comédia com libreto de Arrigo Boito, baseada em Shakespeare. Shakespeare estava destinado a ser, pela máo inspirada de Verdi, a fonte de rejuvenescimento da ópera italiana oitocentista. Macbeth fora a mais inventiva das partituras do período que Verdi designou como os seus "anos de prisão", onde as convençóes oitocentistas, quando não superadas, são postas originalmente ao serviço do drama; quarenta anos depois, Otello, na plena maturidade dos recursos expressivos, volta a renovar a arte lírica, eliminando as formas fechadas e repetitivas da ópera tradicional, e elaborando um novo estilo vocal e uma nova orquestraçáo; finalmente, com Falstaff, Verdi cria, aos oitenta anos, a mais viva e juvenil das óperas cómicas, igualando Mozart. A estreia no São Carlos de Lisboa acontece em 27 de Fevereiro de 1894 e o protagonista, o mesmo da criação milanesa, é Victor Maurel. Seis anos depois, em 1900, Maurel dá o lugar a Mario Sammarco, tendo a seu lado o "Ford" de Giuseppe De Lucca. Os anos 40 do século XX conhecem elencos magníficos: em 1945-46, Gino Bechi (“Falstaff”), Afro Poli (“Ford”), Maria Caniglia ("Alice”), Ebe Stignani (“Quickly"), Camici-Lotti ("Fenton"), Rini Gigli ("Nannetta"); Bechi será o "Falstaff" insubstituível de 48-49, 49-50 e 50-51, com os "Ford" de Mario Borriello e duas vezes Afro Poli; as "Alice" de Renata Tebaldi, duas vezes, e de Maria Caniglia de novo; as "Quickly" sempre de Ebe Stignani; os "Fenton" de Luigi Infantino e duas vezes Guilherme Kjölner; as "Nannetta" de Elena Rizzieri, Fiorella Carmen Forti e Rosanna Carteri. Em 1957-58 e 69-70, Bechi cede o lugar a Tito Gobbi, que partilha o palco, respectivamente, com Renato Cesari e Renato Capecchi 
("Ford"), Orietta Moscucci e Claudia Parada ("Alice”), Franca Sacchi e Fedora Barbieri ("Quickly”), Luigi Alva e Ugo Benelli ("Fenton"), Renata Scotto e Mariella Adani ("Nannetta"). O Falstaff de Maio de 1976 tem a particularidade de ser encenado por uma das mais extraordinárias intérpretes operáticas de todos os tempos, Regina Resnik, que cantava também “Mrs. Quicky”, enquanto o marido, o notável artista plástico Arbit Blatas, desenhava os cenários, produção que seria urgente recuperar e dar a ver ao público. A última ópera de Verdi voltou a São Carlos em 1983-84, 85-86 e 92-93.

Depois de perder Giuseppina (14 de Novembro de 1897), Verdi vai habitar para Milão, onde conclui ainda os Quatro pezzi sacri. À vista do novo século, que o tornou o compositor mais popular nos teatros de todo o mundo, às 14 horas e 50 do dia 27 de Janeiro de 1901, Verdi morre. Uma multidão de trezentas mil pessoas seguiu o cortejo funerário. A Orquestra do Scala, sob a batuta de Arturo Toscanini, tocava o "Va pensiero", do Nabucco. Jamais o nosso pensamento deixou de ir ao seu encontro. 